days and incentive gave reliable differences (both Fs $<1.0$ ), nor did the $8 \%$ group show any initial tendency towards positive contrast when the day-by-day postshift data were examined. However, the persistence of the positive contrast effect with food-pellet groups is indicated by the fact that the food-pellet group surpassed the controls on 8 of the 10 postshift days.

\section{DISCUSSION}

The results thus provide persistent and statistically reliable evidence for positive contrast with qualitative incentive changes in instrumental appetitive acquisition. Moreover, they suggest that at least some of the earlier failures to find such clear evidence of positive contrast were due to the failure to use a sufficiently marked incentive contrast, as seen here in the failure of the $8 \%$ to $32 \%$ shift to produce positive contrast. The role of the lower-than-usual deprivation schedule remains in doubt, in view of the failure of the $8 \%$ group to show contrast even with it, but it is nonetheless possible that low drive contributed to the substantial contrast shown by the group shifted from food pellets to sucrose pellets. Finally, this positive result cannot be interpreted as an artifact of differential weight loss, as Dunham \& Kilp (1969) have recently shown may well be the case for the statistically reliable contrast effects earlier reported by Collier \& Marx (1959). Not only were the slight weight differences unreliable, they were in the direction opposite from that required by this interpretation with the positive contrast group showing more rather than less weight gain.
REFERENCES

AMSEL, A. The role of frustrative non-reward in non-continuous reward situations. Psychological Bulletin, 1958, 55, 102-119.

BLACK, R. W. Shifts in magnitude of reward and contrast effects in instrumental and selective learning: A reinterpretation. Psychological Review, 1968, 78, 114-126.

COLLIER, G., \& MARX, M. H. Changes in performance as a function of shifts in the magnitude of reinforcement. Journal of Experimental Psychology, 1959, 57, 305-309.

CRESPI, L. Quantitative variation of incentive and performance in the white rat. American Joumal of Psychology, 1942, 14, 467-517.

DUNHAM, P. J. Contrasted conditions of reinforcement: A selective critique. Psychological Bulletin, 1968, 69, 295-315.

DUNHAM, P. J., \& KILPS, B. Shifts in magnitude of reinforcement: Confounded factors or contrast effects? Journal of Experimental Psychology, 1969, 79, 373-374.

HELSON, H. Adaptation-level theory: An experimental and systematic approach to behavior. New York: Harper \& Row, 1964.

MARX, M. H. The activation of habits. Psychological Reports, 1966, 19, 527-550.

MARX, M. H., TOMBAUGH, T. N., HATCH, R.S. \& TOMBAUGH, J. W. Controlled operant conditioning boxes with discrete-tria programming for multiple experimental use. Perceptual \& Motor Skills, 1965, 21, 247-254. PEREBOOM, A. C. A note on the Crespi effect Psychological Review, 1957, 64, 263-264.

SCHKIER, A. M. Effects of an upward shift in amount of reinforcer on runway performance of rats. Joumal of Comparative \& Physiological Psychology, 1967, 64, 490-492.

SPENCE, K. W. Behavior theory and conditioning New Haven: Yale University Press, 1956. NOTE

1. This research was supported in part by Grant HD00895 from the National Institute of Child Health and Human Development, Grant GB5853 from the National Science Foundation, and Research Career Award 1-K6-MH22023 from the National Institute of Mental Health.

\title{
Operant conditioning in the Mongolian gerbil'
}

\author{
NANCY CAMPBELL, ${ }^{2}$ DONALD \\ STRANEY, ${ }^{2}$ and ALLEN NEURINGER, \\ Foundation for Research on the Nervous \\ System, 36 The Fenway, Boston, Mass. \\ 02215
}

Mongolian gerbils learned to press a response button to obtain food reward. Responding under three reinforcement schedules was then observed: first, reinforcement occurred after every response; responding was then reinforced on a 15-sec variable-interval schedule; finally, responding was reinforced on a 1-min variable interval.

\section{METHOD}

Four gerbils (three females and one male) from the Tumblebrook Farm stock, 9 weeks old at the beginning of the experiment, were $24 \mathrm{~h}$ food and water deprived during conditioning and were maintained thereafter at between $80 \%$ and $85 \%$ of their normal body weights.

The experimental chamber was a Masonite operant conditioning chamber ( $6 \times 10 \times 10$ in.), containing a Gerbrands Dipper Feeder (cup size $.025 \mathrm{cc}$ ) and a Gerbrands pigeon key (0.5-in.-diam button). A 7-W green bulb transilluminated the response button which was located 1.5 in. above the floor and $3 \mathrm{in}$. to the left of the feeder cup. Each response on the button produced a feedback click from a relay mounted behind the front panel. Reinforcement consisted of 3-sec access to chocolate milk in the feeder. During reinforcement, the response button was darkened and inactivated. A 7.W overhead houselight provided continuous illumination. The experiment was automatically controlled by relays, switches, timers, etc., and responses and time were automatically recorded. Each session terminated after 40 reinforcements.

The gerbils were first shaped (i.e., taught) to press the response button to get access to chocolate milk. The shaping procedure was as described by Skinner (1938). After the animals learned to respond, three different reinforcement schedules were presented: first, eight experimental sessions during which each response produced access to reinforcement (fixed-ratio 1 response, or FR 1); second, 12 sessions during which responses were reinforced on the average of every $15 \mathrm{sec}$, with the interreinforcement intervals randomly distributed (a variable-interval 15-sec, or VI 15-sec); finally, 11 sessions of a 1-min variable-interval schedule, where reinforcements were available on the average of once a minute.

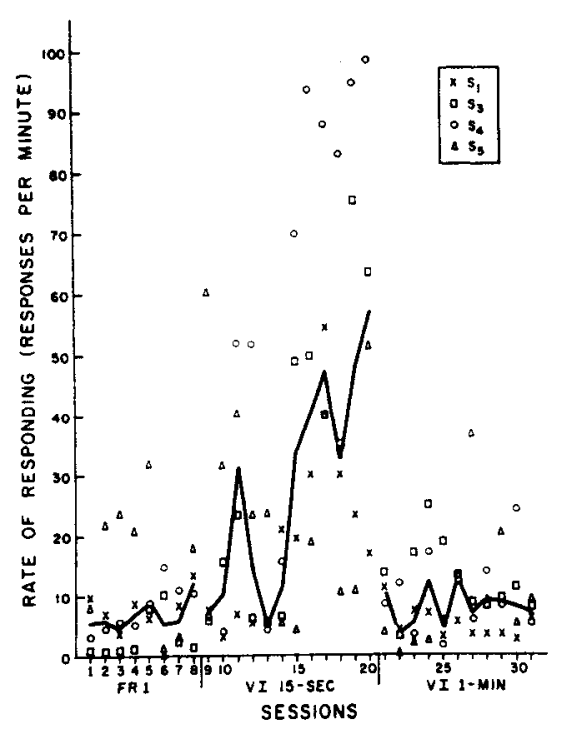

Fig. 1. Rates of responding during every experimental session. Rates were calculated by dividing total number of responses in a session by total session time (excluding reinforcement time). The lines connect the medians of the four gerbils' rates of responding. 


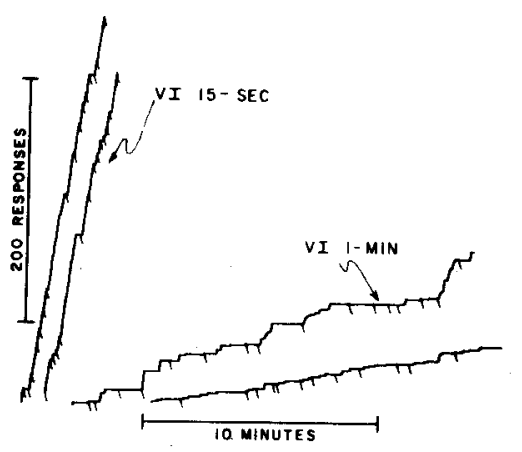

Fig. 2. Selected cumulative records for S 4 under VI 15-sec (left) and VI 1-min (right). The downward slashes denote reinforcement.

\section{RESULTS AND DISCUSSION}

The main finding of this study is that gerbils operated a response button for food reinforcement. Figure 1 shows rates of responding for each gerbil during every experimental session. The rates were low under the FR 1 schedule, increased sharply during the VI 15-sec schedule, and then again decreased under the VI 1-min schedule. Occasional visual monitoring of the animals indicated that periods of relatively rapid responding were sometimes followed by periods during which the gerbils groomed and explored. This observation was supported by the selected cumulative records in Fig. 2, showing pauses after reinforcement and after long bursts of responses.

The gerbil can now be added to the long list of animals that have been shown to emit arbitrary operant responses for food. However, there are interesting differences between the present results and those usually obtained from the common laboratory rat or pigeon. First, the gerbil appeared to engage in considerably more "exploratory" behavior (running about the chamber intermittently) than is normally found in either pigeon or rat. Second, rates of responding under both FR 1 and VI 1-min schedules were lower than with rats or pigeons (Skinner, 1938; Ferster \& Skinner, 1957). These findings might indicate (a) that the reinforcer was relatively weak; (b) that the level of deprivation was not very great; or (c) that, as previously suggested by Schwenkter (1963), food might be a relatively weak reinforcer for the gerbil independent of deprivation level and type or amount of food. By systematically varying deprivation and reinforcement, future experiments can explore these hypotheses.

The Mongolian gerbil (Meriones unguiculatus) was first used as a laboratory animal in Japan in 1933. The strain was introduced into this country in 1952 by Dr. Herbert Axelrod for medical and psychological research (Monroe, 1967). A small rodent, the gerbil is easily maintained in the laboratory, requiring little food, water, and cage cleaning. Psychologists have used the gerbil to study maze learning (Wise $\&$ Parker, 1968), avoidance learning (Boice, Boice, \& Dunham, 1968; Walters, Pearl, \& Rogers, 1963), exploratory behavior (Walters, Pearl, \& Rogers, 1963; Glickman \& Hartz, 1964), shredding behavior (Glickman, Fried, \& Morrison, 1967), spontaneous seizures (Thiessen, Lindzey, \& Friend, 1968), discrimination learning (King, Goodman, \& Rees, 1968), and open-field behavior (Nauman, 1968). However, to the best of our knowledge, no researcher previously reported conditioning gerbils to emit an arbitrary operant response for food reward. In fact, Schwenkter (1963) suggested that because of the extremely powerful "curiosity drive" of the gerbil, conditioning of a food-reinforced response might be difficult or impossible. The study showed, however, that gerbils will press a button for food.

\section{REFERENCES}

BOICE, R., BOICE, C., \& DUNHAM, A. E. Role of docility in avoidance: Gerbils and kangaroo rats in a shuttlebox. Psychonomic Science, 1968 $10,381-382$.

FERSTER, C. B., \& SKINNER, B. F. Schedules of reinforcement. New York: Appleton-Century-Crofts, 1957.

GLICKMAN, S. E., \& HARTZ, K. E. Exploratory behavior in several species of rodents. Journal of Comparative \& Physiological Psychology, 1964, $58,101-104$

GLICKMAN, S. E., FRIED, L., \& MORRISON, B. A. Shredding of nesting material in the Mongolian gerbil. Perceptual \& Motor Skills, 1967, 24, 473-474.

KING, J. E., GOODMAN, R. R., \& REES, W. W. Two- and four-choice object discrimination by gerbils. Journal of Genetic Psychology, 1968, 112, 117-125.

MONROE, B. N. Gerbils. Jersey City, N.J.: T.F.H. Publications, 1967.

NAUMAN, D. J. Open field behavior of the Mongolian gerbil. Psychonomic Science, 1968, 10,163-164.

SCHWENKTER, V. The Gerbil: A new laboratory animal. The Illinois Veteranarian, 1963, 6, 5-9.

SKINNER, B. F. The behavior of organisms. New York: Appleton-Century-Crofts, 1938.

THIESSEN, D. D., LINDZEY, G., \& FRIEND, $H$. C. Spontaneous seizures in the Mongolian gerbil. Psychonomic Science, 1968, 11, 227-228.

WALTERS, G. C., PEARL, J., \& ROGERS, J. V. The gerbil as a subject in behavioral research. Psychological Reports, 1963, 12, 315-318.

WISE, L. M., \& PARKER, E. Discriminative maze learning in the Mongolian gerbil. Psychological Record, 1968, 18, 201-203. NOTES

1. This work was supported by National Institute of Mental Health Grants MH-12108 and MH-15495. We wish to thank Mary Miskella for her assistance during the experiment.

2. Members of the National Science Foundation Brain Sciences Program. 